\title{
A formação do professor de inglês em uma instituição particular
}

\author{
Aurelia Emilia de PAULA FERNANDES \\ Faculdade de Viçosa (FDV) \\ aepfernandes@yahoo.com.br \\ Tatiana Diello BORGES \\ Universidade Federal de Goiás - Jataí (UFG/CAJ) \\ tatiana.diello@gmail.com
}

\begin{abstract}
Resumo
Este artigo relata os resultados obtidos em uma pesquisa de cunho qualitativo e quantitativo realizada com alunos formandos de Letras (Português/Inglês) de uma faculdade particular do sul do Espírito Santo. Nesse estudo, procurouse realizar um levantamento do perfil desses alunos e refletir sobre o processo de formação dos mesmos. O referencial teórico apoiou-se em estudos sobre formação de professores no campo da Linguística Aplicada. Os resultados revelam que os alunos (1) têm pouca familiaridade com as teorias de aquisição de língua estrangeira e com as metodologias de ensino, (2) percebem a disciplina Prática de Ensino de Inglês (PEI) como um momento de treinamento e não de formação, (3) afirmam que esta disciplina é ministrada de modo dogmático e totalmente desvinculado de reflexão, e (4) consideram a PEI irrelevante para o seu processo de formação.
\end{abstract}

Palavras-chave: ensino-aprendizagem de inglês; formação de professor de línguas; prática de ensino de inglês.

\begin{abstract}
This paper reports on the results of a qualitative and quantitative research that aimed at reflecting upon the teacher education process of (Portuguese/English) Letras senior students. The study was carried out at a private college in the south of the state of Espirito Santo. The theoretical basis for this research is taken from studies on teacher education in the field of Applied Linguistics. The results show that students (1) are unfamiliar with foreign language acquisition theories and teaching methodologies, (2) perceive the subject English Teaching Practicum as a moment of training, and
\end{abstract}


not of education, (3) assert that this subject is dogmatically and nonreflectively taught, and (4) consider the English Teaching Practicum irrelevant to their education process.

Keywords: English teaching and learning; language teacher education; English teaching practicum.

\section{Introdução}

Nas últimas décadas, assuntos como a globalização, a era da informação, os avanços na área tecnológica e seus efeitos sobre os povos têm sido amplamente discutidos. Torna-se evidente que frente a tantas e contínuas transformações, os conhecimentos técnicos e científicos se tornam obsoletos tão rapidamente que o conceito de educação definitiva deixa de ter sentido (MATEUS, 2002).

Face ao atual panorama mundial, constata-se a necessidade de formar pessoas capazes de questionar os conhecimentos que lhes são colocados como verdadeiros e de propor novas elaborações (MATEUS, 2002). Uma peça fundamental neste processo de (trans) formação são os professores, incluindo os de língua estrangeira e, principalmente, como foco do presente trabalho, aqueles em formação pré-serviço. Nesse sentido, torna-se imprescindível refletirmos a respeito da formação dos mesmos na graduação.

A formação de professores é uma das áreas em Linguística Aplicada (LA) que mais tem crescido nos últimos tempos (ALMEIDA FILHO, 1999; ARAÚJO, 2003; CELANI, 2003; GIMENEZ, 2002; LEFFA, 2001; PAIVA, 2004, PAIVA, 2005). De acordo com ARAÚJO (2003), desde o início dos anos 90, a formação de professores tem sido uma preocupação dominante em LA, em especial no tocante ao ensino/aprendizagem de línguas estrangeiras. Freitas, Belincanta e Corrêa (2002, p. 48) também observam que, nesta década, surge:

uma grande preocupação com a formação do professor em geral e do professor de LE em particular, resgatando a necessidade de que o mesmo fosse visto como um elemento também fundamental no processo de ensino-aprendizagem, após uma década em que se enfatizaram os modelos e as teorias de aquisição do conhecimento e, consequentemente, o aluno. 
Assim, considerando o interesse e a relevância da formação de professores, procuramos, nesta pesquisa, refletir sobre o processo de formação de professores de língua estrangeira (Inglês) nos cursos de licenciatura em Letras com dupla habilitação, de uma instituição privada.

Este artigo está dividido em quatro partes. Primeiramente, tratamos do referencial teórico, o qual se apoiou em parte da literatura existente em Linguística Aplicada, sobre o tema formação de professores; em seguida, trazemos a metodologia utilizada, apresentando o contexto investigado, os participantes, o instrumento empregado na coleta de dados e a análise dos resultados; na terceira seção, reportamos e discutimos os resultados obtidos e, por fim, apresentamos as considerações finais deste estudo.

\section{Referencial teórico}

Conforme exposto acima, esta pesquisa teve como embasamento teórico o tema formação de professores no campo da Linguística Aplicada.

Ao se realizar uma revisão teórica sobre esse assunto, percebese claramente que os estudos, em sua grande maioria, focalizam a formação do professor reflexivo.

De acordo com Zeichner e Liston (1996), o professor reflexivo é aquele que se examina, estrutura e tenta resolver os dilemas da prática da sala de aula; está atento ao contexto institucional e cultural em que leciona; participa do desenvolvimento do currículo; se envolve nas tentativas de mudança na instituição de ensino na qual atua e se responsabiliza pelo seu desenvolvimento profissional.

Araújo (2004), em consonância com a definição de Zeichner e Liston (1996), entende que o docente reflexivo seja o profissional capaz de analisar criticamente sua prática, por meio de uma maior compreensão de suas crenças a respeito de si mesmo, de seus alunos e da natureza e repercussão do seu ensino.

Alarcão (2002), corroborando as palavras de Zeichner e Liston (1996), afirma que o professor reflexivo é 
aquele que pensa no que faz, que é comprometido com a profissão e se sente autônomo, capaz de tomar decisões e ter opiniões. Ele é, sobretudo, uma pessoa que atende aos contextos em que trabalha, os interpreta e adapta a própria atuação a eles. Os contextos educacionais são extremamente complexos e não há um igual a outro. Eu posso ser obrigado a, numa mesma escola e até numa mesma turma, utilizar práticas diferentes de acordo com o grupo. Portanto, se eu não tiver capacidade de analisar, vou me tornar um tecnocrata.

De acordo com Alarcão, de nada adianta o conhecimento técnico sem a reflexão sobre seu uso na ação. Dessa reflexão surge um novo saber. Todavia essa reflexão só se dá se o sujeito tiver uma base de conhecimentos sobre os quais possa refletir (ALARCÃO, 1996, p. 29 apud ROSSI, 2004, p. 50).

Perrenoud (2002, p. 198) apud Cunha (2003, p. 27), por sua vez, entende que um docente reflexivo

aceita fazer parte do problema. Ele reflete sobre sua própria relação com o saber, com as pessoas, com o poder, com as instituições, com as tecnologias, com o tempo que se vai e com a cooperação, assim como reflete sobre sua forma de superar limites ou de tornar mais eficazes os seus gestos técnicos. Enfim, uma prática reflexiva metódica insere-se no horário de trabalho como uma rotina. Não uma rotina soporífera, mas uma rotina paradoxal, um estado de alerta permanente (Grifos no original).

$\mathrm{O}$ autor, considerando que, nos dias atuais, as sociedades se transformam, criam-se e desfazem-se e que as tecnologias alteram o trabalho, a comunicação, a vida cotidiana e, até mesmo, o pensamento, questiona quais lições desse mundo globalizado podem ser tiradas para a formação de professores. Para Perrenoud (1999), seguramente, convém reforçar a preparação desses profissionais para uma prática reflexiva, a inovação e a cooperação. Em suas palavras: "prática reflexiva e participação crítica [devem ser] entendida como orientações prioritárias da formação de professores" (PERRENOUD, 1999, p. 5). 
Perrenoud (1999) observa que a prática reflexiva jamais é um trabalho completamente solitário. Ela se apóia em conversas informais, feedback de colegas/parceiros, auto-análises do trabalho, reflexões sobre sua qualidade, avaliações do que se faz. De acordo com o autor,

a prática reflexiva até pode ser solitária, mas ela passa também pelos grupos, apela para especialistas externos, insere-se em redes, isto é, apóia-se sobre formações, oferecendo os instrumentos ou as bases teóricas para melhor compreender os processos em jogo e melhor compreender a si mesmo (PERRENOUD, 1999, p. 11).

Ainda para Perrenoud (1999), a prática reflexiva só pode incorporar-se ao habitus profissional se estiver no centro do plano de formação, tornando-se, assim, o motor da articulação teoria/prática.

No que diz respeito à participação crítica, o outro propósito da formação de professores, de acordo com Perrenoud (1999), se expressa em quatro níveis: 1) Aprender a cooperar e a atuar em rede; 2) Aprender a viver a escola como uma comunidade educativa; 3) Aprender a sentir-se membro de uma verdadeira profissão e a ser responsável por ela; e, 4) Aprender a dialogar com a sociedade. Para o autor, para que a participação crítica se torne um componente do habitus profissional dos professores, da mesma maneira que a atitude reflexiva, é preciso instaurar dispositivos de formação precisos e desenvolver competências fundadas sobre saberes oriundos das ciências humanas.

É possível perceber claramente dois aspectos extremamente importantes para este autor concernentes à formação de professores. Primeiramente, a prática reflexiva e a participação crítica, além de serem os dois objetivos desta formação, também representam suas maiores alavancas, pois, segundo ele, é funcionando em uma postura reflexiva e em uma participação crítica que os alunos tirarão o melhor proveito de uma formação em alternância. Em segundo lugar, de acordo com este autor, o que podemos esperar da formação de professores é "que ela esclareça os futuros professores, os desembaraços dessa ideia simples de que ensinar é transmitir um saber, acima de qualquer suspeita a crianças ávidas de assimilá-lo, 
independentemente de sua origem social" (PERRENOUD, 1999, p. 14 - grifo no original).

Autoras como Celani (2001), Mateus (2002) e Vieira-Abrahão (2002) corroboram o argumento de Perrenoud (1999) de que a prática reflexiva e a participação crítica devem ser entendidas como orientações prioritárias da formação de professores.

Para Celani (2001), a educação reflexiva, o ensino reflexivo são emancipatórios. Têm por objetivo aprimorar a prática, estimular a racionalidade e a autonomia dos professores e daquilo que é ensinado. Assim, para a autora, é apenas por meio da prática reflexiva que o docente poderá obter o domínio da complexidade e da imprevisibilidade, "que é o que encontrará no mundo, na escola, na sala de aula" (CELANI, 2001, p. 35-36). Do mesmo modo que Perrenoud (1999), Celani (2001) também acredita que prática reflexiva realizada de modo isolado não é suficiente. É necessária a presença de uma participação crítica.

Mateus (2002, p. 8) também entende que o conceito de prática reflexiva, assim como o de participação crítica, configura-se como "um caminho factível para o desenvolvimento de professores capazes de lidar com o desafio de aprender a aprender". Assim como Celani (2001), a autora também considera que o docente crítico-reflexivo busca a sua emancipação, e também a de seus alunos.

Vieira-Abrahão (2002), além de concordar que o ensino reflexivo apresenta-se como excelente maneira de construir conscientemente uma prática de ensino, pondera que ele é um processo dificultoso, o qual requer mudanças no pensar e agir, e adoção, por parte do professor, de uma postura crítica em relação ao seu próprio desempenho, desafiando suas próprias crenças. Ainda de acordo com a autora, a implementação de uma prática reflexiva envolve reflexão sobre as influências que a prática pedagógica realizada exerce na formação da sociedade como um todo e na formação do próprio aluno.

As pesquisas em Linguística Aplicada que têm se ocupado da formação de professores, além de focalizarem o docente reflexivo, como exposto até o momento, também têm apontado para a questão de que as universidades, por excelência de sua natureza, de modo geral, em seus programas de formação, não têm entendido a prática reflexiva e a participação crítica como orientações prioritárias da formação de professores (MATEUS, 2002; PERRENOUD, 1999). 
De acordo com Mateus (2002), paradoxalmente, as universidades que deveriam promover uma formação de professores orientada para a prática reflexiva e a participação crítica, realizam, em sua grande maioria, uma formação de técnicos, tanto nas áreas dos conhecimentos quanto em pesquisa. Em nosso estudo, pudemos constatar claramente este caráter de treinamento que a formação de professores em nosso país, em geral, tem se ancorado. Para os participantes desta pesquisa, a disciplina Prática de Ensino de Inglês é entendida como um momento de treinamento e não de formação, além de ser percebida como totalmente desvinculada de reflexão.

Perrenoud (1999, p. 15), por sua vez, acredita que para as universidades, em sua grande maioria, ultrapassarem este caráter de treinamento de seus cursos de formação para um que, de fato, tenha a prática reflexiva e a participação crítica como seu cerne, é preciso "desenvolver dispositivos específicos como, por exemplo, análises de práticas, estudos de caso, vídeo-formação, escrita clínica, técnicas de auto-observação e de esclarecimento [...]" (grifo no original).

Dois aspectos relacionados ao tema formação de professores na área de Linguística Aplicada podem ser facilmente observados ao término desta seção. Primeiramente, como vimos, os estudos sobre o assunto, em sua ampla maioria, têm focalizado a formação do professor reflexivo, pois, de acordo com diversos pesquisadores da área, a prática reflexiva e crítica, dentre outras questões, pode colaborar para a autonomia e emancipação dos professores, assim como de seus alunos (ALARCÃO, 2002; ARAÚJO, 2004; CELANI, 2001; MATEUS, 2002; PERRENOUD, 1999; VIEIRA-ABRAHÃO, 2002; ZEICHNER; LISTON, 1996).

Em segundo lugar, as pesquisas sobre formação de professores também salientam a relevância de, cada vez mais, refletirmos criticamente a respeito da formação que tem sido oferecida nos cursos de Letras, já que, como veremos nos resultados obtidos nesta pesquisa, parece que essa formação, em geral, não tem sido pautada nos conceitos de prática reflexiva e na participação crítica. 


\section{Metodologia}

Este trabalho configura-se como uma pesquisa que se utilizou do paradigma qualitativo. O objetivo deste estudo foi realizar um levantamento do perfil dos alunos formandos de Letras (Português/Inglês) de uma instituição privada do sul do Espírito Santo e refletir sobre o processo de formação dos mesmos.

Esta pesquisa foi realizada com 22 alunos do $8^{\circ}$ período de Licenciatura em Letras com habilitação em Português e Inglês de uma faculdade particular do sul do estado do Espírito Santo. A instituição foi criada em 1967 e iniciou seu funcionamento em 1973. Atualmente, além das Licenciaturas em Letras, Matemática, História, Biologia, Pedagogia e Normal Superior, a instituição também oferece Bacharelados em Farmácia, Psicologia e Enfermagem.

Os alunos são oriundos da cidade em que a instituição se localiza e de vários municípios vizinhos. Vale ressaltar que o curso de Letras é noturno e os alunos, ao ingressarem, possuíam pouca familiaridade com a língua inglesa. Com exceção de 5\% que haviam frequentado cursos de inglês anteriormente. Ressaltamos também que $90 \%$ dos alunos trabalham durante o dia. Esses dados foram coletados em pesquisa realizada pela primeira autora deste artigo, que foi subchefe e professora do Departamento de Letras da instituição, durante oito anos e também professora dos alunos-participantes durante $\mathrm{o} 1^{\circ}$ e $2^{\circ}$ período do curso. A faixa etária dos alunos ao ingressarem no curso varia entre 18 e 35 anos.

Em relação ao instrumento de coleta de dados, utilizamos um questionário semiaberto. A opção pelo uso de questionário deveu-se, principalmente, ao fato de que, de acordo com Johnson (1992), a aplicação deste requer menos tempo e menos custos. O objetivo da utilização deste instrumento era realizar um levantamento de como tem sido a formação dos alunos formandos de Letras da instituição em que o estudo foi conduzido ${ }^{1}$. O questionário foi constituído por sete

\footnotetext{
${ }^{1}$ Gostaríamos de ressaltar que somos conscientes da limitação de se empregar apenas um instrumento, pois, como argumentam muito bem Allwright e Bailey (1991), Johnson (1992) e Nunan (1992), a utilização de um maior número de instrumentos, amplia a validade e a confiabilidade da pesquisa em questão. Entretanto, acreditamos que o questionário da forma como foi elaborado, com perguntas fechadas e abertas, tenha garantido uma maior liberdade e espontaneidade de expressão dos participantes,
} 
perguntas. Na primeira, perguntamos como o aluno-professor avalia o seu nível de inglês (em relação às quatro habilidades) e o do seu professor de Prática de Ensino. Na segunda questão, perguntamos se os participantes já ministram aulas de inglês ou de outra disciplina e, em caso negativo, se pretendem ministrar. Com a terceira pergunta, tínhamos a intenção de descobrir qual a avaliação que os alunosprofessores fazem da disciplina Prática de Ensino de Inglês. Na quarta, perguntamos como eles percebem essa disciplina, oferecendo três alternativas de resposta: momento de treinamento, momento de formação e/ou momento de reflexão. No quinto item, apresentamos um quadro com uma síntese de como alguns autores abordam o papel do professor de línguas do final do século XIX até os dias atuais (MAZA, 1997) e perguntamos: (1) com qual (is) abordagem (ns) os participantes, sinceramente, se identificavam; (2) em qual (is) eles encaixariam seu (a) professor (a) de língua inglesa da graduação; e, (3) se já haviam lido ou ouvido falar de alguns dos autores apresentados. Na sexta pergunta, solicitamos que os alunos-professores citassem um ou mais autores (brasileiros ou não) com os quais tivessem se identificado durante as leituras na disciplina de Prática de Ensino de Inglês e, na sétima questão, perguntamos se os participantes haviam estudado, durante a graduação, sobre os métodos de ensino de língua inglesa e, em caso afirmativo, qual (is) teria (m) sido este (s) método (os).

Quanto à análise dos dados, dois procedimentos foram adotados. Primeiramente, procedemos a uma leitura detalhada das respostas dadas no questionário pelos participantes, realizando, assim, uma análise interpretativista dos dados. Após a categorização qualitativa, efetuamos análise de porcentagens.

\section{Análise dos dados}

Existe na Linguística Aplicada uma preocupação com a preparação dos professores de inglês que geralmente são confrontados com ideais teóricos e linguísticos, mas, posteriormente, se deparam

compensado, assim, em parte, a ausência de outros instrumentos no processo de coleta de dados. 
com as adversidades e limitações bruscas na vida profissional. Vários autores no campo da Linguística Aplicada têm discutido o conceito de competência, em especial Almeida Filho (1993, 1999), que desenvolveu um modelo que inclui cinco competências mínimas do professor de LE (Línguas Estrangeiras): competência implícita, linguístico-comunicativa, teórica, aplicada e profissional.

Nesta seção, apresentamos os resultados obtidos na pesquisa realizada, respondendo ao objetivo desta - refletir sobre o processo de formação de professores de língua estrangeira (inglês), tendo como pressuposto as competências mínimas do professor de LE sugeridas por Almeida Filho (1993, 1999), no curso de licenciatura em Letras com dupla habilitação, de uma instituição privada.

\subsection{Auto-avaliação do nível de inglês dos participantes: produção e compreensão oral, leitura e escrita}

Objetivou-se com esta auto-avaliação conduzir os participantes a uma ação reflexiva, pois desde o início da década de 90 , com os estudos de Schön (1992), muito se tem falado em professor reflexivo. Entretanto, sabemos que o docente não se torna reflexivo sozinho, principalmente, em nosso entendimento, aquele que está em formação. Este precisa de alguém que o ajude, levando-o a responder perguntas que, em princípio, ele não é capaz de se fazer. Ao aprofundar o nível das questões, ele aprofunda o próprio pensamento (ALARCÃO, 2002).

Segundo a auto-avaliação, o nível de inglês em produção e compreensão oral desta língua revelou-se idêntico, $75 \%$ consideramno bom e $25 \%$ fraco. Vale esclarecer que apenas $5 \%$ dos participantes haviam tido contato com cursinhos de inglês ao ingressarem na instituição e, após avaliação oral dos alunos-participantes, constatamos que esse bom refere-se ao nível básico.

$\mathrm{Na}$ auto-avaliação do inglês na habilidade leitura, os resultados obtidos causaram-nos estranheza: $50 \%$ acreditam que têm uma leitura em língua inglesa fraca e os outros $50 \%$ a consideram boa. Estranheza causada pelo fato de que os participantes, além da graduação, tiveram contato anteriormente com o idioma durante o ensino fundamental e médio, o qual, em sua grande maioria, se restringe ao foco na leitura.

Após conversas com o professor de Literatura Inglesa e NorteAmericana, constatamos que os alunos encontram grandes dificuldades 
ao se depararem com os textos das referidas literaturas e um dos recursos que o professor utiliza para amenizar a situação é muitas vezes apresentar textos em português. Possivelmente, essa atitude tenha agravado o problema.

$\mathrm{Na}$ habilidade escrita, alguns participantes se auto-avaliaram de uma forma um pouco mais otimista: 59\% consideram-se fracos, porém $33 \%$ consideram-se muito bons e $8 \%$ excelentes.

\subsection{Nível de inglês do professor de Prática de Ensino de Inglês segundo os participantes: produção e compreensão oral, leitura e escrita}

Outro aspecto solicitado aos alunos-participantes foi que avaliassem o nível de inglês do professor de Prática de Ensino de Inglês, considerando as quatro habilidades.

$\mathrm{Na}$ avaliação que os alunos fizeram sobre o professor da referida disciplina, os resultados mostram que eles consideram o nível de inglês do professor fraco, em todas as habilidades: 59\% o consideram fraco em termos de produção oral, leitura e escrita, e $67 \%$ em relação à compreensão oral.

Estes resultados parecem sugerir que os alunos reconhecem que precisam de profissionais mais qualificados para orientá-los. Cabenos ressaltar que o docente em questão possui o título de Especialista em Língua Portuguesa. Talvez este dado justifique o resultado.

\subsection{Participantes que lecionam}

Interessou-nos, também, nesta pesquisa, visto que o curso de Letras dessa IES é noturno, e a grande maioria dos alunos trabalha durante o dia, saber se os mesmos já são professores em pré-serviço ou se trabalham em áreas distintas de sua formação.

Os resultados apontam que 50\% dos alunos deste curso de Letras trabalham em áreas que não são da Educação e $50 \%$ já são professores em pré-serviço.

Desses professores em pré-serviço, apenas 8\% atuam especificamente na disciplina de inglês, $17 \%$ atuam com inglês e outras disciplinas como português ou artes e $25 \%$ lecionam somente outras disciplinas. 


\subsection{Participantes que pretendem lecionar}

Quanto ao interesse dos alunos-participantes em atuarem como profissionais da Educação e até mesmo na sua área de formação, foi outro aspecto surpreendente.

Os resultados mostram que (1) $25 \%$ dos participantes pretendem lecionar inglês e outras disciplinas, já que possuirão dupla habilitação, (2) 25\% pretendem lecionar inglês, (3) $8 \%$ só pretendem ministrar as outras disciplinas para as quais serão habilitados: português e literatura, e (4) $42 \%$ não pretendem seguir a profissão. Resultado semelhante também tem sido encontrado no projeto de pesquisa (em andamento) "Desvendando as crenças sobre ensino/aprendizagem de língua inglesa de alunos, ingressantes e concluintes de Letras (Inglês): um estudo comparativo", coordenado pela segunda autora deste artigo. Em 2008 e 2009, o projeto contou com a participação de cinco alunos formandos do curso de Letras (Inglês) de uma universidade pública do sudoeste goiano. Destes, quatro afirmaram em entrevista que não pretendem ser professores de língua inglesa, sendo a principal razão, para três dos participantes, a falta de competência linguística. Em suas palavras:

Quando eu terminar o meu curso eu não vou poder ser professor. Eu vou ter que procurar um curso [de inglês] pra eu fazer porque senão eu vou passar vergonha em sala de aula $\left(\mathrm{DAVI}^{2}\right.$, entrevista).

Eu não tenho intenção de dar aula, infelizmente. Eu não tenho segurança nenhuma de ensinar alguma coisa pra um aluno. Enquanto eu não tiver uma base, uma confiança na língua eu não vou dar aula (KAMILLA, entrevista).

Eu, com o meu nível [refere-se à língua inglesa], não quero responsabilidade pra mim de ensinar outra pessoa do jeito que eu tô [refere-se a sua competência lingüística em inglês]. Eu acho que eu preciso estudar mais para ser

\footnotetext{
${ }^{2}$ Para resultados relacionados às crenças sobre ensino/aprendizagem de língua inglesa dos alunos formandos em Letras (Inglês), Davi e Paty, ver Borges, Lago e Oliveira (2009a) e Borges, Lago e Oliveira (2009b).
} 
professora. Não tô terminando o curso com a intenção de ser professora. Por enquanto, eu não estou pensando em dar aula, não (PATY, entrevista).

Eu acho que eu nunca vou dar aula de inglês porque eu não tenho a intenção de ser professora. Talvez eu trabalhe com tradução porque achei bárbaro, fantástico, amei! Eu não acho que os meus quatros anos de Letras (Inglês) ficaram perdidos. De jeito nenhum! Eu vou aproveitá-los, mas não atuando como professora (LIA, entrevista).

\subsection{Avaliação da disciplina de Prática de Ensino de Inglês segundo os participantes}

Um aspecto, que não pode ser esquecido, é a própria formação que estes professores recebem nos cursos de Prática de Ensino durante a Licenciatura. Segundo Vieira-Abrahão (1997), tais cursos deveriam habilitar os graduandos a exercer a docência, mas sua duração média de 75 horas semestrais é insuficiente se analisada em relação à complexidade das habilidades linguísticas e pedagógicas esperadas de um futuro professor de língua estrangeira. Consequentemente, os cursos acabam por colaborar na formação de profissionais acríticos, os quais integrarão o quadro já problemático do ensino de LEs. A base formativa dos professores, segundo Pimenta e Lima (2008) apud Xavier (2009), tem como alicerce conhecimentos teóricos e metodológicos que comportem compreender a escola, os sistemas de ensino e as políticas educacionais.

Os dados nos apontam que apenas $15 \%$ dos participantes afirmam que a disciplina de Prática de Ensino de Inglês os ajudou com teorias de aquisição de língua estrangeira e teorias de ensino/aprendizagem. Outros $15 \%$ afirmam que a disciplina os ajudou apenas com teorias de ensino e aprendizagem. Já $31 \%$ asseveram que a disciplina os ajudou somente na didática, disciplina que já havia sido ministrada por profissionais do Departamento de Educação no $3^{\circ}$ semestre do curso, e $39 \%$ expressam que a disciplina os ajudou de outras formas.

Gostaríamos de ressaltar que após conversas e análise do plano de ensino, observamos que o professor de Prática não possui 
familiaridade com as teorias de aquisição e ensino/aprendizagem de língua estrangeira. Somente teorias de ensino/aprendizagem gerais.

\subsection{Percepção dos alunos-professores no tocante à disciplina Prática de Ensino de Inglês}

Prado (2004) apud Xavier (2009) postula que a prática deve ser entendida como o desenvolvimento das ações desempenhadas naquele momento, sempre pautada por uma teoria. Essas ações deverão estar presentes nos cursos de formação de professores e nos estágios curriculares, e a conexão entre teoria e prática deverá ser um movimento contínuo entre saber e fazer na busca de significados na gestão, administração e resolução de situações próprias do ambiente da educação escolar.

Foi possível observar que a maioria dos alunos (67\%) percebe esta disciplina como um momento de treinamento. Este resultado (1) parece sugerir que esses alunos-professores ainda não sabem diferenciar treinamento de formação, assunto amplamente discutido por Leffa (2001), e (2) ratifica o que comprovou Silva (2001, p. 15):

\footnotetext{
Em várias regiões do Brasil, os cursos de Letras ainda são vistos como cursos de treinamento de professores, em que alunos chegam despreparados, sem noções básicas da língua estrangeira que pretendem ensinar, e em que pouco se discute sobre o processo de formação de professores dentro das abordagens mais atuais de ensino.
}

Concordamos com Oliveira (2004) ao afirmar que formar professores vai além de treinamento técnico, é preparar os alunos para o exercício da profissão, abrindo espaço para posicionamentos críticosreflexivos, que eles possam principalmente contrastar teorias e formar as suas próprias sobre o que seja ensinar.

Os demais participantes consideram que a Prática de Ensino de Inglês é um momento de formação (17\%) e de reflexão (17\%). 


\subsection{Participantes que durante o curso de graduação estudaram sobre métodos de ensino de língua inglesa}

Os resultados mostram que $92 \%$ dos participantes não estudaram sobre esses métodos e, quanto aos $8 \%$ que afirmam tê-los estudado, especulamos que, com base na experiência da primeira autora neste contexto, provavelmente, o fizeram de forma autônoma.

\subsection{Autores com os quais os alunos se identificaram durante as leituras na disciplina de Prática de Ensino de Inglês}

Ao serem questionados quanto às teorias (leituras) realizadas no decorrer da disciplina PEI, os resultados são de $100 \%$ afirmando que não havia leituras, pois os $17 \%$ que disseram ter lido Paul Auster, se equivocaram. Paul Auster é um autor pós-modernista da Literatura Norte-Americana.

Não há dúvida da necessidade de capacitação teórica - ou competência aplicada, nos dizeres de Almeida Filho (1993, p.(?)) para os profissionais de LEs. Como Libâneo (1997, p. 173) frisa muito bem, "[...] tornar o professor co-construtor de seu processo de trabalho implica que ele avalie judiciosamente sua prática a partir da reflexão em cima de seu trabalho, com base em teoria".

\section{Considerações Finais}

Nesta pesquisa procuramos refletir sobre o processo de formação de professores de língua inglesa nos cursos de licenciatura em Letras com dupla habilitação, de uma instituição privada, pois se queremos falar de formação docente, precisamos traçar o perfil do profissional de língua estrangeira que queremos e que o país precisa.

Este estudo indica um ponto que é comum em outros estudos: a deficiência dos cursos de formação de professores. Assim, corrobora, em parte, o que outros já vêm demonstrando: (1) que em muitas faculdades particulares, a formação do professor de língua estrangeira fica a cargo de pedagogos sem nenhuma qualificação específica para a tarefa; (2) a existência de ementas e programas que se sustentam em bibliografia desatualizada e teorias que não dialogam com a prática; (3) 


\section{A formação do professor de inglês em uma instituição particular}

que os projetos de estágio permanecem no antigo modelo de observação e regência; e (4) que as atividades de pesquisa, previstas na resolução de formação de professor, ainda são incipientes nesta instituição, a qual ainda não possui programas consolidados de iniciação científica, monitoria, extensão ou outras atividades complementares.

Entretanto, consideramos relevante destacar que é preciso inovar, mas acima de tudo é imprescindível ter consciência crítica face à novidade, à inovação, ou seja, que se não deve repetir o velho pelo simples fato de ser velho, nem de aceitar o novo pelo mesmo propósito, mas valida-los. E isso é um processo de transformação que jamais ocorrerá se for encarado como um processo isolado. É necessário o envolvimento dos colegas de profissão e da comunidade em questão.

Ao pensar em programas de formação de professores devemos estar conscientes que formar-los vai além de treinamento técnico, significa preparar os alunos para o exercício da profissão, abrindo espaço para posicionamentos críticos-reflexivos, ou seja, que eles possam principalmente contrastar teorias e formar as suas próprias sobre o que seja ensinar. Em resumo, formação de professores é um projeto político para transformações sociais.

Assim, uma sugestão seria talvez a criação de projetos interinstitucionais para os desafios que se apresentam: a definição da base de conhecimento profissional do curso de Letras (transmitir o máximo possível de conhecimentos nos campos dos estudos linguísticos); a redefinição da abordagem articuladora da teoria/prática, que tem se mostrado tão preocupante nos cursos de formação de professores; a ressignificação da crença de que apenas os professores de estágio são formadores; e a articulação entre a academia e os órgãos governamentais para que as políticas públicas se atenham à necessidade de se formarem profissionais qualificados.

Esperamos que esses resultados e considerações possam, de alguma forma, contribuir para a continuidade desta tão necessária reflexão ${ }^{3}$.

\footnotetext{
${ }^{3}$ Agradecemos à $\operatorname{Prof}^{\mathrm{a}} \operatorname{Dr}^{\mathrm{a}}$ Neuda Alves do Lago pela leitura deste trabalho e pelos comentários.
} 


\section{Referências}

ALARCÃO, Isabel. Refletir na prática. Nova Escola, n. 154, 2002. Disponível em: <http://novaescola.abril.com.br/index.htm?ed/154 ago02/html/fala me

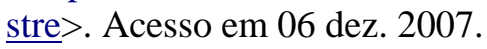

- Reflexão crítica sobre o pensamento de Donald Schön e os programas de formação de professores. In: (Org.). Formação reflexiva de professores: estratégias de supervisão. Porto: Porto Editora, 1996. p. 11-39.

ALLWRIGHT, Dick; BAILEY, Kathleen. M. Focus on the language classroom. Cambridge: Cambridge University Press, 1991.

ALMEIDA FILHO, José C. P. Dimensões comunicativas no ensino de línguas. Campinas: Pontes, 1993.

ALMEIDA FILHO, José C. P. (Org.). O Professor de língua estrangeira em formação. Campinas: Pontes, 1999.

ARAÚJO, Antonia D. Crenças e concepções do professor-educador sobre a formação do professor de língua estrangeira. In: GIMENEZ, Telma (Org.). Ensinando e aprendendo inglês na universidade: formação de professores em tempos de mudança. Londrina: ABRAPUI, 2003. p. 85-94.

ARAÚJO, Denise R. Crenças de professores de inglês de escolas públicas sobre o papel do bom aprendiz: um estudo de caso. 2004. 233 f. Dissertação (Mestrado em Lingüística Aplicada). Faculdade de Letras, Universidade Federal de Minas Gerais, Belo Horizonte, 2004.

BORGES, Tatiana. D; LAGO, Neuda. A. do; OLIVEIRA, Vitalino. G. "Se você não tem domínio da sua própria língua, como vai aprender ou ensinar uma segunda língua?": crenças de uma formanda em Letras (Inglês) sobre ensino e aprendizagem de língua inglesa. In: Anais do XXV Congresso de Educação do Sudoeste Goiano/Edição Nacional. Jataí: UFG/CAJ, p. 1-10, 2009 a. 
. Um aluno formando de Letras (Inglês): quais são suas crenças acerca do processo de ensino/aprendizagem de língua inglesa? Revista Intercâmbio, vol. XIX, p. 125-150, 2009 b.

CELANI, Maria Antonieta A. Ensino de línguas estrangeiras: ocupação ou profissão. In: LEFFA, Vilson J. (Org.). O professor de linguas: construindo a profissão. Pelotas: EDUCAT, 2001. p. 21-40.

JOHNSON, Donna. Approaches to research in second language learning. New York: Longman, 1992.

LEFFA, Vilson J. O professor de línguas: construindo a profissão. Pelotas: EDICAT, 2001.

LIBÂNEO, José C. Pedagogia e modernidade: presente e futuro da Escola. In: GUIRALDELLI, Jr., Paulo (Org.). Infância, escola e modernidade. Curitiba: Editora da Universidade Federal do Paraná, 1997. p. 127-176.

MAZA, Fernanda T. O papel do professor de língua estrangeira: uma retrospectiva. In: CELANI, Maria Antonieta A. (Org.). Ensino de segunda língua: redescobrindo as origens. São Paulo: EDUC, 1997. p. 87-105.

MATEUS, Elaine F. Educação contemporânea e o desafio da formação continuada. In: GIMENEZ, Telma (Org.). Trajetórias na formação de professores de línguas. Londrina: Editora UEL, 2002. p. 3-14.

NUNAN, David. Research methods in language learning. Cambridge: Cambridge University Press, 1992.

OLIVEIRA, Eliane. C. A prática educacional de professoras iniciantes nas escolas de ciclos. In: VIEIRA-ABRAHÃO, Maria Helena (Org.). Práticas de ensino de língua estrangeira: experiências e reflexões. Campinas: Pontes Editores, 2004. p. 45-59. 
PERRENOUD, Philippe. Formar professores em contextos sociais em mudança: prática reflexiva e participação crítica. Revista Brasileira de Educação, n. 12, p. 5-21, 1999.

- A prática reflexiva no ofício do professor: profissionalização e razão pedagógica. Porto Alegre: Artmed Editora, 2002.PIMENTA, Selma G.; LIMA, Maria do Socorro L. Estágio e docência. São Paulo: Cortez, 2008.

PRADO, Eliane M. As práticas dos professores de História nas escolas estaduais paulistas nas décadas de 1970 e 1980. 2004. Tese (Doutorado em Educação) - Faculdade de Educação, Pontifícia Universidade Católica de São Paulo, São Paulo, 2004.

SCHÖN, Donald A. La formación de profesionales reflexivos: hacia un nuevo disefio de la enseñanza y el aprendizaje en las profesiones. Barcelona: Paidós, 1992.

SILVA, Luciana. O. Crenças sobre aprendizagem de língua estrangeira de alunos formandos de Letras: um estudo comparativo. 2001. 137 f. Dissertação (Mestrado em Lingüística Aplicada). Faculdade de Letras, Universidade Federal de Minas Gerais, Belo Horizonte, 2001.

VIEIRA-ABRAHÃO, Maria Helena. Repensando o curso de Letras: Habilitação em língua estrangeira. In: ANAIS da $49^{\circ}$ Reunião Anual da SBPC. Belo Horizonte: UFMG, 1997.

XAVIER, Jean P. B. O estágio supervisionado no curso de licenciatura em língua inglesa em uma instituição de ensino superior na cidade de Paranaguá. In: Anais do IX Congresso Nacional de Educação EDUCERE - III Encontro Sul Brasileiro de Psicopedagogia. PUCPR. 2009.

Disponível em: http://www.pucpr.br/eventos/educere/educere2009/anais/pdf/3035_132 6.pdf>. Acesso em 13 mai. 2010.

Recebido em: 15/05/2010 Aceito em: 18/12/2011 
A formação do professor de inglês em uma instituição particular

Title: The English teacher education at a private college 